\title{
Libro: De la dependencia a la autogestión laboral. Sobre la reconstrucción de experiencias colectivas de trabajo en la Argentina contemporánea
}

Gabriela Wyczykier

Editorial Prometeo, Buenos Aires, 2009. (334 pp.)

\section{Melina Perbellini}

Becaria del Consejo Nacional de Investigaciones Científicas y Técnicas en el Centro de Investigaciones y Estudios del Trabajo (CIET), Facultad de Ciencia Política y Relaciones Internacionales de la Universidad Nacional de Rosario, Argentina.

E-mail: melinaperbellini@gmail.com

Desde la aparición de las empresas recuperadas como fenómeno en nuestro país -ligado a las estrategias sociales y defensivas iniciadas con furor a partir de la crisis de 2001- mucho se ha escrito sobre el tema en lo que va de la década. Sin embargo, la mayoría de los estudios se centra en un análisis meramente descriptivo de alguna de las experiencias. Este no es el caso del libro -tesis doctoral- de Gabriela Wyczykier. La autora ha sobrepasado el límite descriptivo y se ha sumergido en un análisis potente y profundo. A su vez, va más allá de la investigación de las empresas recuperadas aparecidas luego de la crisis, y extiende su análisis a la emergencia y desarrollo de experiencias de autogestión del trabajo en el periodo 1990-2006.

La hipótesis de trabajo que va a atravesar toda la investigación es la idea de las experiencias de autogestión del trabajo como un fenómeno de recolectivización laboral, en un contexto de significativa descolectivización social y política. Afirma la autora: “(...) ante la crisis de desintegración socio ocupacional y la pérdida de marcos y relaciones colectivas que afectó a importantes segmentos de la población local durante el periodo elegido, la autogestión laboral se conformó como una respuesta no generalizable de los sectores populares, para evitar quedar desplazados y excluidos de aquellos espacios laborales y sociales que habian contribuido a trazar trayectorias profesionales en gran parte de los trabajadores que integraron estas experiencias".

Otro de los puntos centrales que va a marcar la diferencia de este estudio con investigaciones anteriores, es que el concepto de recolectivización laboral le sirve a la autora para distinguir el proceso autogestionario surgido a lo largo de los años '90 y principios del milenio, de otras experiencias antecesoras de colectivización laboral, tanto nacionales como internacionales.

Wyczykier observa, retomando a Castel y Svampa, cómo los cambios ocurridos en el mercado de trabajo en las últimas décadas afectaron a la clase trabajadora, alterando su capacidad de establecer respuestas colectivas ante los riesgos de desintegración. En este contexto, los individuos transitaron una profunda desorientación política potenciada por la incapacidad de los colectivos representativos -sindicatos- para seguir siendo el sostén protector de los trabajadores. Es así que para la autora, las experiencias de autogestión laboral-experiencias de 
recolectivización laboral- son el fruto directo de este proceso descolectivizador que condicionó las trayectorias laborales de una porción de la sociedad, originando un importante número de trabajadores desocupados.

Nuestra autora va a elegir, para abordar su investigación, cinco colectivos laborales basándose en la categorización de experiencias de autogestión "desde arriba" y "desde abajo" -según hayan surgido por la influencia directa del Estado o por la motivación de los propios trabajadores en colaboración con otras organizaciones-. Dentro del primer grupo sitúa el caso de una cooperativa de trabajadores que surgió con la privatización de YPF en el año 1992 (Cooperativa de Trabajo Taller Naval). El segundo grupo está conformado por cuatro casos que forman parte directamente del fenómeno de las empresas recuperadas. Una de ellas apareció antes de la crisis de 2001 (Cooperativa de Trabajo Adabor), y las otras tres corresponden a empresas recuperadas por sus trabajadores durante el año 2002 (Cooperativa Artes Gráficas El Sol, Cooperativa de Trabajo L B., FASINPAT).

El libro se va a organizar en tres grandes partes y está dividido a su vez en ocho capítulos. La primera, que comprende dos capítulos, se centra en el análisis de los antecedentes internacionales y nacionales sobre procesos de autogestión laboral. En el primer capítulo caracteriza una serie de experiencias históricas que remiten a prácticas laborales autogestionarias llevadas adelante por colectivos obreros en diversos territorios y momentos históricos. Lo interesante de este apartado, más allá de la enunciación de las diferentes experiencias históricas, es el análisis de la variación del concepto de autogestión a través del tiempo, el cual abarca desde propuestas libertarias ligadas a la emancipación de la clase trabajadora y la democratización de las relaciones de trabajo en los países socialistas hasta su utilización contemporánea en la cual la autogestión se asume como estrategias de supervivencia colectiva de los trabajadores.

El segundo capítulo recorre la historia del movimiento obrero en nuestro país con la intención de contextualizar las experiencias históricas de autoorganización del trabajo. Si bien las mismas no han sido numerosas, en algunos períodos se vislumbra la aparición de una serie de procesos que permiten registrar su presencia.

La segunda parte - desde nuestro punto de vista la más contundente en términos teóricos- se centra en el análisis de dos de los conceptos centrales de la investigación: descolectivización y recolectivización del trabajo. En el capítulo tres se abordan los aportes de diferentes autores -Castel, Beck, Giddens, Lash- para tematizar sobre los procesos de descolectivización e individualización. Por otro lado, se analizan los cambios ocurridos en el mercado de trabajo local en la década del ' 90 , y las principales respuestas desplegadas por los trabajadores.

En el capítulo cuatro se presentan los alcances del proceso de recolectivización y los niveles y modalidades que lo caracterizan. En el nivel más básico, el término refiere a la reconstrucción de situaciones colectivas de trabajo. Un segundo nivel indica la reconfiguración de relaciones laborales colectivas, que supuso la posibilidad de quedar ligados a una experiencia laboral que había estructurado trayectorias profesionales en una empresa particular y que otorgaba una identidad. Un tercer nivel alude a la configuración de una nueva sociabilidad intergrupal. Un 
cuarto nivel refiere a las relaciones de solidaridad organizativa que se desarrollaron entre los colectivos de trabajadores de las empresas autogestionadas, que ocuparon un rol central en acompañar los procesos de autogestión "desde abajo".

El capítulo cinco se dedica a la caracterización de las organizaciones de representación de intereses de los trabajadores de las empresas recuperadas. En este punto, se vinculan estos movimientos con la noción de Movimiento Social Reivindicativo, realizada por Melucci (1994). Según esta noción, las acciones desplegadas por estos actores no tuvieron como finalidad el trastocamiento de las relaciones sociales y laborales capitalistas, sino que buscaron cuestionar una manera de distribuir los recursos sociales en el interior del sistema político y económico.

En la tercera parte, Wyczykier analiza directamente las experiencias autogestionarias "desde arriba" y "desde abajo" como espacio de conflicto, de sociabilidad y de politización. En el capítulo seis se analizan las acciones colectivas y los conflictos llevados adelante por los trabajadores de las cuatro empresas recuperadas y por lo trabajadores de la experiencia autogestionaria producto de la privatización de YPF.

En el capítulo siete se caracteriza al espacio autogestionario como un escenario donde se revitalizaron y se recrearon relaciones de sociabilidad en torno al trabajo, y se reflexiona sobre las dimensiones ligadas a la cultura del trabajo. Por otro lado, se argumenta sobre los desafíos y cambios de orden subjetivo y objetivo que los trabajadores debieron afrontar en la organización autogestionaria del trabajo, reflexionando acerca de las modalidades adoptadas para distribuir los ingresos y para incorporar nuevos miembros.

En el último capítulo, se problematiza sobre las prácticas políticas desplegadas por estos colectivos haciendo hincapié en las modalidades que fue adquiriendo la relación entre los colectivos de trabajo y las organizaciones sociales, políticas y gremiales. Por otro lado, se plantean las opciones políticas tendientes a encontrar una solución legal definitiva para la apropiación de los medios de producción en las empresas recuperadas.

En las conclusiones la autora reorganiza los principales argumentos esgrimidos a lo largo de todo el libro y vuelve a reafirmar su hipótesis: "El pasaje de la dependencia a la autogestión laboral en estos años contuvo para nosotros este elemento común que las reunió en un universo de sentido compartido: la de ser experiencias de recolectivización laboral".

\section{Referencias Bibliográficas}

A. MELUCCI (1994), "Asumir un compromiso: identidad y movilización en los movimientos sociales", en Zona Abierta $\mathrm{N}^{\circ} 69$, Madrid. 